\title{
Fatigue Life Prognosis of a Light Aircraft Landing Gear Leg
}

\author{
David Gerhardinger ${ }^{1}$, Anita Domitrović ${ }^{2}$, and Ernest Bazijanac ${ }^{3}$ \\ ${ }^{1,2,3}$ Faculty of Transport and Traffic Sciences, University of Zagreb, Croatia, 10000 \\ dgerhardinger@fpz.unizg.hr \\ adomitrovic@fpz.unizg.hr \\ ebazijanac@fpz.unizg.hr
}

\begin{abstract}
Aircraft components are subject to fatigue damage. The prediction of fatigue life has a significant influence on maintenance and flight operations. Light aircraft, designed for recreational purposes, have vital components that are subject to a hard time maintenance approach. The focus of this paper is on a simple method for predicting fatigue life. The method is applied to a light aircraft's fixed landing gear leg. The landing gear leg is modeled in a computer-aided design environment. The load spectrum is determined based on a characteristic flight profile. Principal strains are determined with finite element analysis. Fatigue life is calculated with the Coffin-Manson low cycle fatigue relation. The Palmgren-Miner rule is applied, and cumulative damage is determined. The results are compared to actual landing gear leg fatigue damage and the hard time replacement interval, which is given in the corresponding maintenance manual.
\end{abstract}

\section{INTRODUCTION}

Aircraft landing gear designs include many engineering disciplines. Landing gears have been described by Rastogi (2016) as "the essential intermediary between the aircraft and catastrophe". According to Campbell and Lahey (1984), a total of 1885 fatigue failure related accidents were identified on a worldwide scale; these accidents resulted in 2240 deaths. Campbell (1984) identified engine/transmission failure and landing gear failure as the most common cause of aircraft accidents, with a yearly average of 100 serious fatigue accidents involving 69 fixed-wing and 31 rotary-wing aircraft. The investigation also showed that there was an average of 18 fatal accidents resulting from metal fatigue.

Fatigue is defined as a process of cycle-by-cycle damage accumulation in a material undergoing fluctuating stresses and strains (Cui, 2002). The aircraft landing gear is, therefore, subject to fatigue damage during its operational life. Fatigue

David Gerhardinger et al. This is an open-access article distributed under the terms of the Creative Commons Attribution 3.0 United States License, which permits unrestricted use, distribution, and reproduction in any medium, provided the original author and source are credited. failures are usually prevented by design, testing, load monitoring, inspection, and the replacement of parts at scheduled intervals. The prevention of fatigue failure by design often means a "safe life" design approach. The "safe life" design approach states that any fatigue damage will not progress to a catastrophic condition, during its predicted operational lifetime. This design approach is frequently applied to light aircraft. Today's light aircraft maintenance is often based on a fixed, and previously predicted time frame for component replacement, called "hard time replacement interval". The "hard time replacement interval" is part of a preventive maintenance strategy, aiming to avoid future faults, by carrying out maintenance actions at predetermined intervals, or according to prescribed criteria. Light aircraft maintenance is also subject to corrective and condition-based maintenance strategies. Corrective maintenance is applied after fault detection. Whereas, condition-based maintenance relies on Condition Monitoring (CM), which is based on sensor data, occurrence reports, and/or inspection reports.

The landing gear leg, which is the subject of this article, is designed with a safe life design approach in mind, recognizing the need for a preventive maintenance strategy. The problem with preventive maintenance and a "hard time replacement interval" is that light aircraft are operated in various load and environment conditions, making it hard to predict its life during the design phase accurately. Regardless of the incorporated safety factor, specific load, and environment conditions can lead to a shorter operational life than prescribed, possibly leading to catastrophic failure. One similar case was the inspiration for this study. A light aircraft landing gear leg failed during takeoff. The landing gear leg still had $30 \%$ of its "hard time replacement interval" left. Operational conditions varied considerably and were not favorable for the last $6 \%$ of the operation time, meaning that the aircraft was overweight. A simple, reliable, and robust method for Remaining Useful Life (RUL) prediction, dependent on operational conditions, would have helped to avoid such an occurrence.

The design phase of any aircraft is subject to certification specification compliance. This compliance means that any 
system must be designed to withstand intended maximum loads times the prescribed safety factor. Usually, light sport aircraft have a safety factor around 3, depending on the observed part. Also, all systems must have maintenance and/or replacement interval. In the case of the subject landing gear leg, the replacement interval was at 300 operation hours, according to the manufacturer's maintenance manual. The subject aircraft had to respect the very challenging maximum takeoff mass of less than $472.5 \mathrm{~kg}$. (European Parliament and Council Regulation (EC) No 216/2008 (2008)), no part of it could be over-engineered. This was also true for the landing gear assembly, which was designed a relatively low, but still permittable, safety factor. Maintenance reports observed landing gear leg fracturing before the prescribed replacement time. This occurrence was due to a combination of unfavorable and illicit circumstances: rough runways, an overweight aircraft, and novice pilots, with over-emphasized inputs, were amongst them.

In order to estimate fatigue life, this article proposes five main steps, Figure 1. First, a source of fatigue relevant data, i.e., stress/strain, is determined and utilized. The CAD and FEM analysis software AUTODESK Fusion 360® was chosen for this purpose. Second, a probable location of fatigue failure is identified. The Von Mises yield criterion and empirical data can act as an indicator. Third, an appropriate fatigue life relation has to be selected. The Coffin-Manson low cycle fatigue relation was chosen for the subject landing gear leg. Fourth, data relevant to fatigue life relation is gathered, and fatigue life is calculated. Fifth, cumulative damage is calculated with the Palmgren-Miner rule and compared with existing maintenance data.

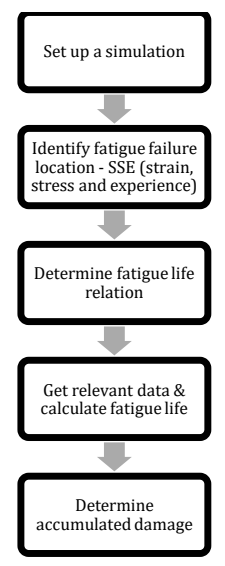

Figure 1. Proposed steps to determine fatigue life.

Following this article section is a detailed description of the simulation setup.

\section{SIMULATION SETUP}

Acquiring stress and strain data is the first proposed step. This step is due to stress and strain being a relevant indicator for probable future failure as well as assisting in selecting the appropriate fatigue life relation. High stresses and strains lead to lower fatigue life. In order to do this, a CAD model was developed. The model then had to be subjected to external loads and constraints approximating real conditions, corresponding to significant load profiles and construction limitations. The load profile significance was determined by stress and strain amplitude, the higher the stress/strain amplitudes, the bigger their impact on fatigue life.

\subsection{The Main Wheel Landing Gear System Cad Model}

The CAD model consists of seven parts shown in Figure 2. The landing gear frame (Figure 2, part 1), two landing gear legs (Figure 2, part 2A \& 2B), two-wheel axle attachments (Figure 2, parts 3A \& 3B), and two-wheel axles (Figure 2, parts $4 \mathrm{~A} \& 4 \mathrm{~B})$.

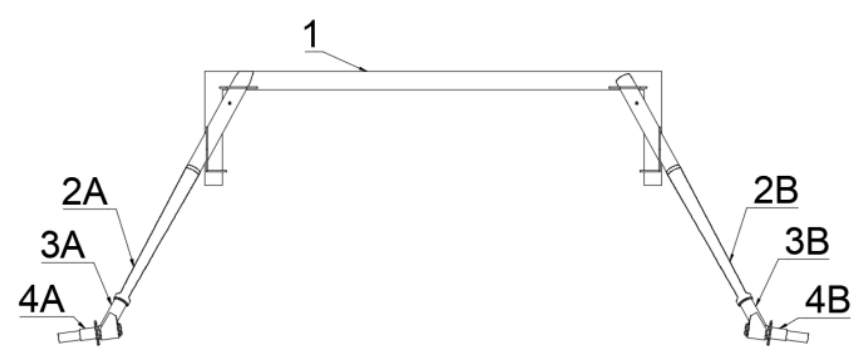

Figure 2. Landing gear assembly.

The landing gear frame is shown with its basic dimensions in Figure 3. The frame material is standard structural steel ASTM A36. According to Autodesk Fusion 360® material library, its stress-strain curve follows ASME B\&PV Code 2015, Section VIII, Division 3, KD-231. The frame's mechanical properties are: Young's modulus $200 \mathrm{GPa}$, Poisson's ratio 0.26, shear modulus 79365.079 MPa, density $7.800 \mathrm{~g} / \mathrm{cm}^{3}$, yield strength $248.211 \mathrm{MPa}$ and tensile strength 475.738 MPa.

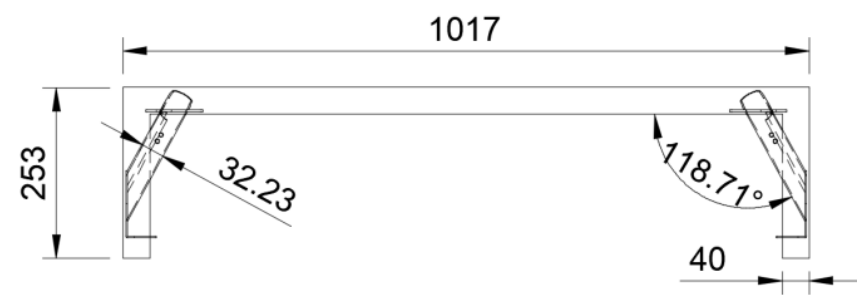

Figure 3. Landing gear frame, dimensions in [mm].

Since the subject of interest is the landing gear leg, Figure 4. shows its exact geometry.

The landing gear leg was designed to be made from heattreated aluminum-zinc alloy, Al 7075-T6. Its mechanical properties are Young's modulus $71.12 \mathrm{GPa}$, Poisson's ratio 0.33 , shear modulus $26900 \mathrm{MPa}$, density $2.810 \mathrm{~g} / \mathrm{cm}^{3}$, yield strength $512 \mathrm{MPa}$, and tensile strength $572 \mathrm{MPa}$. It is designed from one piece of cylindrical aluminum alloy rod. On both ends of the rod, there are pinholes intended to fasten the landing gear leg to the rest of the construction. 

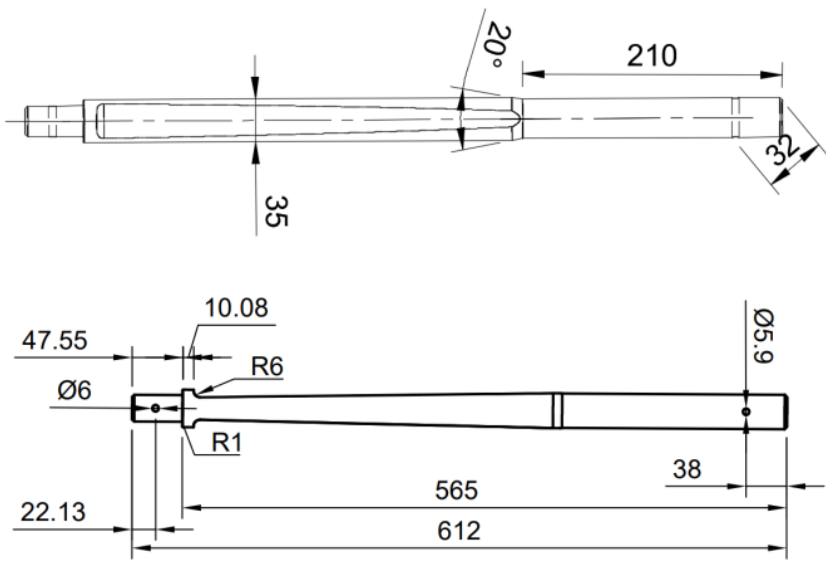

Figure 4. Landing gear leg, dimensions in [mm].

The landing gear wheel axle attachment is shown in Figure 5. It is made from carbon steel and has the following mechanical properties: Young's modulus $200 \mathrm{GPa}$, Poisson's ratio 0.29, shear modulus 79700. MPa, density $7.85 \mathrm{~g} / \mathrm{cm}^{3}$, yield strength $350 \mathrm{MPa}$, and tensile strength $420 \mathrm{MPa}$.

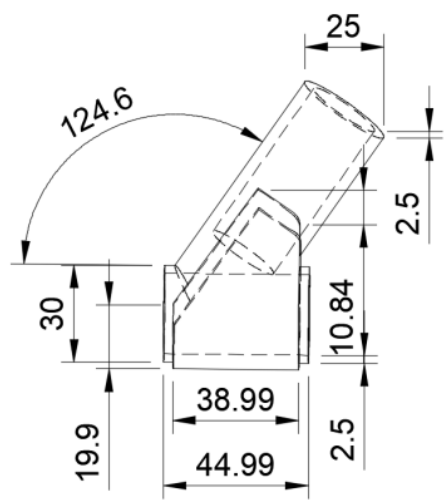

Figure 5. Landing gear wheel axle attachment and wheel axle, dimensions in [mm].

The wheel axle is made from the same material as the landing gear frame, Figure 3. The landing gear wheel bearing is installed onto the shaft of the wheel axle and transfers a parabolic force distribution onto the axle shaft, as shown in section 2.2.
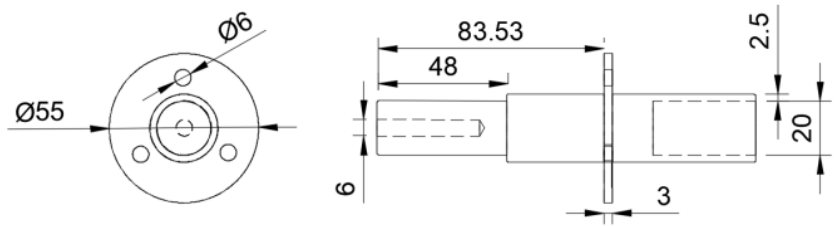

Figure 6. Wheel axle, dimensions in [mm].

\subsection{Landing Gear Leg Load Profiles}

Fatigue life is significantly impacted by external factors, such as aircraft operation induced loads and their frequency. The resulting stresses and strains, acting upon the landing gear leg, are key factors in fatigue life determination. For this reason, three characteristic load profiles have been chosen. The first one is during taxi and, while aerodynamic forces can be neglected. This load profile is characteristic because it acts on the landing gear leg with the highest load intensity, the full aircraft weight being unopposed by aerodynamic lift. The second load profile is while the aircraft takes off and lands, with the nose wheel up in the air. The characteristic of this load profile is the altered load angle, shifted relative to vertical, and load intensity opposed by aerodynamic lift. The third load profile is during cruise flight, while its own landing gear leg, and attached wheel weight, are pulling towards the center of gravity. This load profile is interesting because the load direction is reversed in relation to the first load profile, assuming the landing gear is non-retractable.

For better fatigue life estimation, two takeoff masses where considered, the maximum takeoff mass and the takeoff mass with one $75 \mathrm{~kg}$ pilot. In the first case, aeronautical regulations governing the production of light sport aircraft, at the time of designing the subject aircraft, had a prescribed maximum takeoff mass, including the ballistic rescue system, of 473.15 $\mathrm{kg}$. Those masses sum up to an average pilot and copilot mass of $150 \mathrm{~kg}$, meaning $75 \mathrm{~kg}$ pilot and equivalent copilot mass. The amount of fuel adds up to an additional $33 \mathrm{~kg}$. of mass, and another $10 \mathrm{~kg}$ weighs down the baggage area. The second load case assumes the aircraft is flown by only one pilot; whose body mass is $75 \mathrm{~kg}$. In this case, the fuel and baggage mass was left the same as in load case 1 .

\subsubsection{The First Load Profile}

During the first load profile, the landing gear leg is loaded multiaxial; this is due to design geometry. The total aircraft mass is distributed according to the manufacturer's mass and balance sheet. Figure 7. depicts the aircraft in question, the tricycle landing gear layout is labeled A, for main landing gear (left and right), and $\mathrm{B}$, for the nose landing gear. According to mass and balance distribution, while the aircraft is stationary on the ground having a full $473.15 \mathrm{~kg}$, the left, and right main landing gear, labeled $\mathrm{A}$, take on a total of $403.64 \mathrm{~kg}$., meaning $201.82 \mathrm{~kg}$, acting on each landing gear leg. The nose landing gear takes on the rest of $69.37 \mathrm{~kg}$. Since the nose landing gear is of a different construction type, and subject to different loads, it is not considered further. 


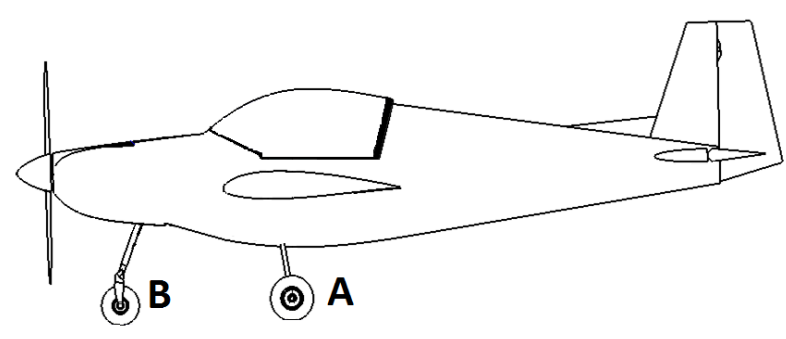

Figure 7. Aircraft on ground weight distribution.

In order to determine the first load profile, load intensity, and distribution had to be identified. While the aircraft was stationary and/or the aerodynamic forces where negligible, the load vector intensity was calculated by multiplying the total mass acting upon one main landing gear leg and the gravitational constant $\mathrm{g}=9.81 \mathrm{~m} / \mathrm{s}^{2}$, its value was $1979 \mathrm{~N}$.

The second case had only one pilot in the aircraft and the same fuel and baggage mass. The load vector intensity, in this case, was $1666 \mathrm{~N}$.

The calculated load intensity was applied to the wheel axle in a parabolic distribution, normal to the surface. This kind of distribution is a typical force pattern between bearings and wheel axles. Also, there is no tension component. The load is distributed around half of the axle face, $180^{\circ}$, while the other face half is unloaded. The force has its maximum at the center of the force pattern, parallel to the vertical axis, reducing its intensity in a circular direction away from the vertical, as shown in Figure 8.
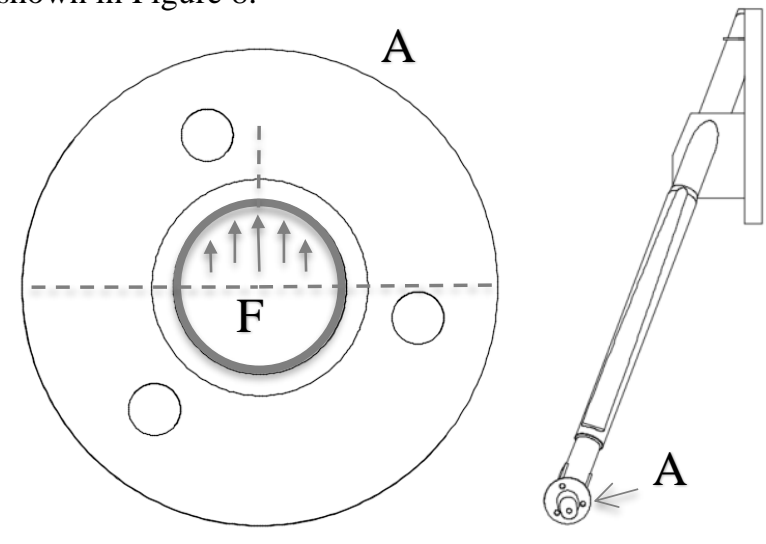

Figure 8. First load phase load profile.

This load profile can be assumed for all operations where aerodynamic influences are negligible.

\subsubsection{The Second Load Profile}

The second load profile was chosen because of the deviation in load angle acting on the landing gear leg, and varying but significant load intensity, due to varying aerodynamic forces. While the aircraft is accelerating, the nose landing gear will lift off first. The weight acting on one landing gear leg is then equal to the difference between generated aerodynamic lift and the total aircraft weight divided between the two main landing gear legs. During takeoff, the aircraft accelerates and also changes its pitch angle, from the moment the front wheel lifts off to complete takeoff. The load acting on the landing gear leg is, therefore, a variable dependent on these two parameters. The calculation of exact stresses, resulting from this variable load, complicates the study, and does not significantly contribute to overall result accuracy. This is why it was decided to continue calculation with a mean angle and load intensity.

The lift intensity of the second load profile ranges from zero to the total aircraft weight. The aircraft's maximum takeoff mass was assumed. The aircraft maximum takeoff weight is then $4641.6 \mathrm{~N}$. The mean weight acting on the landing gear legs is half its value, $2320.8 \mathrm{~N}$, or $1160.4 \mathrm{~N}$ on one leg, respectively, marked $\mathrm{F}$ in Figure 9.

In case only one pilot is present, the takeoff weight would be $3905 \mathrm{~N}$. Half of that, $1952 \mathrm{~N}$ being the mean value. The weight acting on one landing gear leg is then $976 \mathrm{~N}$.

As mentioned previously, the second load variable is the angle of bearing load distribution. This angle corresponds to the aircraft's pitch angle. The subject aircraft's pitch angle varies, during takeoff, from $0^{\circ}$ to $5^{\circ}$, according to the manufacturer's pilot operating handbook. The assumption of a mean pitch angle of $2.5^{\circ}$ will not compromise result integrity. This load distribution is displayed in Figure 9.
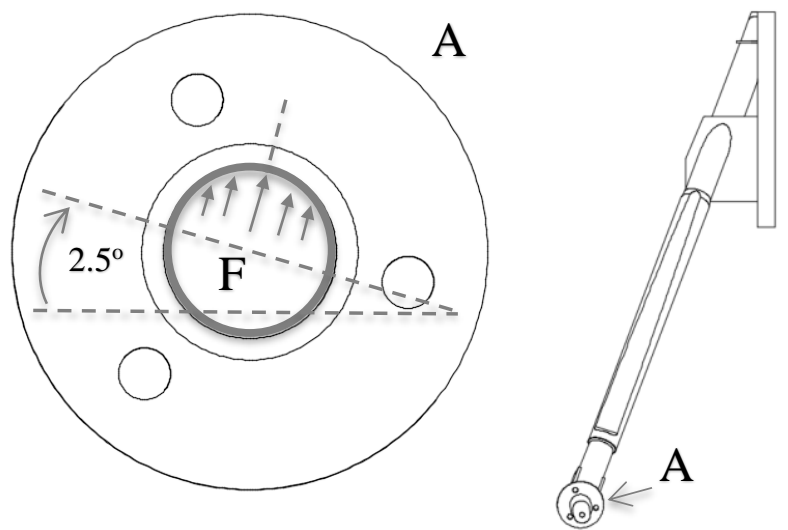

Figure 9. Second load phase load protıle.

An equivalent load distribution can be assumed for the landing procedure.

\subsubsection{The Third Load Profile}

The third load profile has a distinctive load direction. Since this load profile is represented by cruise flight, load orientation is aligned with the direction of gravitational pull. Load distribution is the same bearing load type from the first and second load phase. However, load intensity is very different; only the attached wheel acts on the landing gear leg. According to the manufacturer, the landing gear wheel mass 
is $2.7 \mathrm{~kg}$., meaning a weight of $26.49 \mathrm{~N}$. This load profile is displayed in Figure 10.
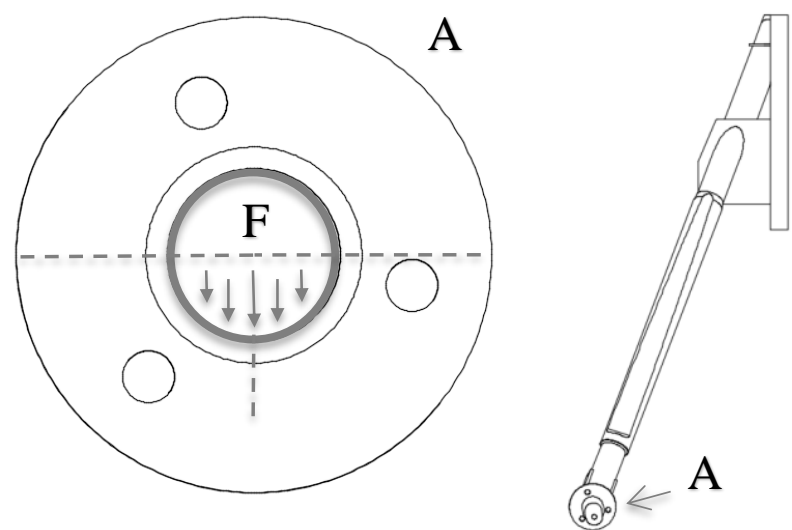

Figure 10. Third load phase load protıle.

The load intensity of this load profile remains equal, regardless of the pilot, fuel, and baggage mass, within the acceptable takeoff mass limits.

\subsection{Constraints}

The landing gear frame is attached to the aircraft frame support surface with screws. A crucial fact being, the whole back surface of the frame is supported by the aircraft, as displayed in Figure 11. The landing gear frame CAD model constraint status was therefore set to fixed.

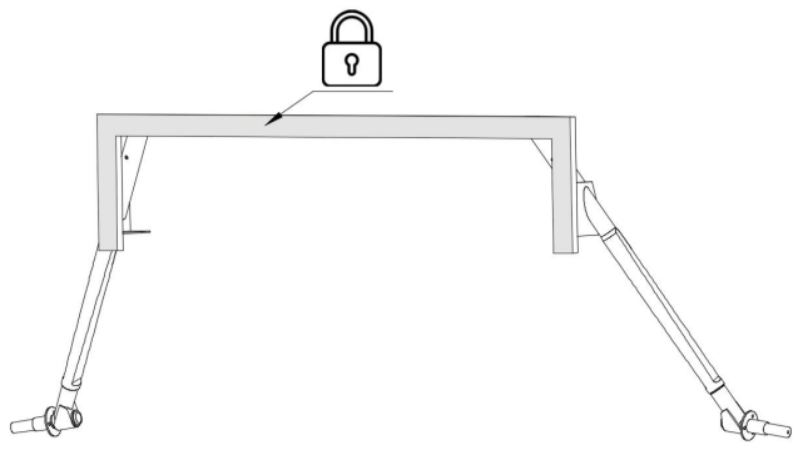

Figure 11. Landing gear frame constraint.

The contact interaction between all surfaces experiencing mutual contact has been set to bonded, with the tolerance level set to $0.1 \mathrm{~mm}$.

\subsection{Mesh Settings}

The finite element mesh size was decided to be model-based, set at $2 \%$ of the subject component. In order to reduce computation resource consumption, a minimum element size was set up at $5 \%$ of the average model component size. Mesh elements were of tetrahedral shape, 167945 in total, covering the model surface.

\section{FEM ANALYSIS AND RESULTS}

The results of all three load profiles showed significant Von Mises stress in two landing gear leg regions. These results were expected because of the landing gear leg specific geometric features and load profile, as well as maintenance observations; both regions are displayed in Figure 12.

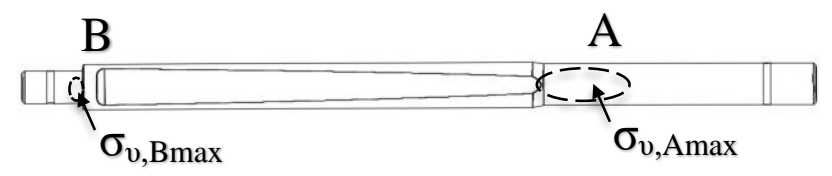

Figure 12. Landing gear leg stress concentration locations.

Region A and B were therefore chosen for further analysis. The exact position of maximum Von Mises stress values, within the mentioned regions, were pinpointed for each load profile, Figure 12.

The extracted Von Mises stress data allows future failure location and causal load profile prediction. In this light, the most probable failure will occur during the first load profile in region $\mathrm{A}$. The second probable failure will, again, occur during the first load profile, in region B. Subsequent failure probability is distributed accordingly, from higher to lower value in Table 1.

\begin{tabular}{|c|c|c|}
\hline & $\begin{array}{l}\sigma_{v, \mathrm{Amax}} \\
{[\mathrm{MPa}]}\end{array}$ & $\begin{array}{l}\sigma_{v, \mathrm{Bmax}} \\
{[\mathrm{MPa}]}\end{array}$ \\
\hline LP1 $1_{\text {MTOM }}$ & 160.6 & 123 \\
\hline LP2 & 92.13 & 67.39 \\
\hline LP3 $3_{\text {Мтом }}$ & 9.07 & 7.37 \\
\hline LP1 & 135 & 103.5 \\
\hline LP2 & 77.37 & 56.57 \\
\hline LP3 & 9.07 & 7.37 \\
\hline
\end{tabular}

Table 1. Maximum Von Mises stress in load regions A and B for all load profiles 1 to 3 .

First and third principal stress and strain data were extracted for load profile 1 to 3 , in the locations of maximum VonMises stress, displayed in Table 2.

\begin{tabular}{|l|c|c|c|c|}
\cline { 2 - 5 } \multicolumn{1}{c|}{} & $\begin{array}{c}\sigma_{1} \\
{[\mathrm{MPa}]}\end{array}$ & $\begin{array}{c}\sigma_{3} \\
{[\mathrm{MPa}]}\end{array}$ & $\begin{array}{c}\varepsilon_{1} \\
{\left[10^{-4}\right]}\end{array}$ & $\begin{array}{c}\varepsilon_{3} \\
{\left[10^{-4}\right]}\end{array}$ \\
\hline LP1 $1_{\text {A,MTOM }}$ & 192.6 & 44.98 & 40.19 & -21.05 \\
\hline LP2 ${ }_{\text {A,MTOM }}$ & 113 & 27.8 & 23.07 & -12.21 \\
\hline LP3 ${ }_{\text {A,MTOM }}$ & -0.557 & -9.894 & 1.175 & -2.271 \\
\hline LP1 & & & \\
\hline LP,MTOM & -18.71 & -150.4 & 15.25 & -28.69 \\
\hline
\end{tabular}




\begin{tabular}{|c|c|c|c|c|}
\hline LP3 $_{\mathrm{B}, \mathrm{MTOM}}$ & 8.71 & 0.7058 & 1.662 & -0.877 \\
\hline $\mathrm{LP}_{\mathrm{A}}$ & 161.9 & 37.79 & 29.87 & -14.03 \\
\hline $\mathrm{LP} 2_{\mathrm{A}}$ & 94.9 & 23.32 & 17.43 & -7.951 \\
\hline $\mathrm{LP} 3_{\mathrm{A}}$ & -0.557 & -9.894 & 1.175 & -2.271 \\
\hline $\mathrm{LP} 1_{\mathrm{B}}$ & -14.5 & -125.7 & 13.12 & -24.08 \\
\hline $\mathrm{LP} 2_{\mathrm{B}}$ & -3.469 & -65.37 & 7.349 & -12.89 \\
\hline $\mathrm{LP} 3_{\mathrm{B}}$ & 8.71 & 0.7058 & 1.662 & -0.877 \\
\hline
\end{tabular}

Table 2. Stress and strain in regions A and B.

\section{FATIGUE LIFE}

In order to assess the fatigue life of the load profile 1 to 3 , the Coffin-Manson low cycle fatigue relation was applied (Campbell, 2008).

$$
\frac{\Delta \varepsilon_{p}}{2}=\varepsilon_{f}^{\prime}\left(2 N_{f}\right)^{c}
$$

The FEM analysis software allowed extraction of maximum first and third principal strain. In order to calculate the plastic strain amplitude, the elastic strain was subtracted from the total strain amplitude, equation 2.

$$
\Delta \varepsilon_{p}=\Delta \varepsilon_{\text {total }}-\Delta \varepsilon_{e}=\Delta \varepsilon_{\text {total }}-\frac{\sigma_{\text {principal }}}{E}
$$

The total strain was calculated as the ratio between maximum principal stress, first or third, whichever had a higher intensity, and the materials module of elasticity (Boller \& Seeger, 1987).

$$
\Delta \varepsilon_{\text {total }}=\varepsilon_{1}+\varepsilon_{2}
$$

The fatigue ductility coefficient and the fatigue ductility exponent were taken from (Boller \& Seeger, 1987), for an aluminum 7075-T6 rod, $19 \mathrm{~mm}$. in diameter, at $23^{\circ} \mathrm{C}$.

Table 3. shows the data that was used in order to determine the number of strain reversals to failure, $2 N_{f}$, boldly written values where used in equation (3), (2), and (1).

The calculated strain reversals to failure, given in Table 3., represent aircraft landing gear leg fatigue life for the corresponding load profile and location. When predicting fatigue life in terms of a number of flights or flight hours, the first and second load profile have to be divided by two, since they are encountered twice, during each flight. It can be observed that the first load profile in the case of MTOM and single pilot takeoff mass, for locations A and B, cause the shortest fatigue life. After that, the second shortest fatigue life results from the second load profile. The third load profile leads to the longest fatigue life. This result is emphasized by the number of load profile encounters mentioned above. The calculated fatigue life intensities and their order make

\begin{tabular}{|c|c|c|c|}
\hline & $\mathrm{LP} 1_{\mathrm{A}, \mathrm{MTOM}}$ & $\mathrm{LP} 2_{\mathrm{A}, \mathrm{MTOM}}$ & $\begin{array}{l}\mathrm{LP} 3_{\mathrm{A}} \text {, } \\
\text { мтом }\end{array}$ \\
\hline$\sigma_{1}[\mathrm{MPa}]$ & 192.6 & 113 & -0.557 \\
\hline$\sigma_{3}[\mathrm{MPa}]$ & 44.98 & 27.8 & -9.894 \\
\hline$\varepsilon_{1}\left[10^{-4}\right]$ & 40.19 & 23.07 & 1.175 \\
\hline$\varepsilon_{3}\left[10^{-4}\right]$ & -21.05 & -12.21 & -2.271 \\
\hline$\varepsilon_{f}^{\prime}$ & 0.446 & 0.446 & 0.446 \\
\hline$c$ & -0.759 & -0.759 & -0.759 \\
\hline \multirow[t]{2}{*}{$2 N_{f}$} & 762 & 1612 & 31099 \\
\hline & $\mathrm{LP} 1_{\mathrm{B}, \mathrm{MTOM}}$ & $\mathrm{LP} 2_{\mathrm{B}, \mathrm{MTOM}}$ & LP3 $3_{\text {B,MTOM }}$ \\
\hline$\sigma_{1}[\mathrm{MPa}]$ & -18.71 & -4.132 & 8.71 \\
\hline$\sigma_{3}[\mathrm{MPa}]$ & -150.4 & -77.87 & 0.7058 \\
\hline$\varepsilon_{1}\left[10^{-4}\right]$ & 15.25 & 8.75 & 1.662 \\
\hline$\varepsilon_{3}\left[10^{-4}\right]$ & -28.69 & -15.35 & -0.877 \\
\hline$\varepsilon_{f}^{\prime}$ & 0.446 & 0.446 & 0.446 \\
\hline c & -0.759 & -0.759 & -0.759 \\
\hline \multirow[t]{2}{*}{$2 N_{f}$} & 1302 & 2690 & 56904 \\
\hline & $\mathrm{LP} 1_{\mathrm{A}}$ & $\mathrm{LP} 2_{\mathrm{A}}$ & $\mathrm{LP} 3_{\mathrm{A}}$ \\
\hline$\sigma_{1}[\mathrm{MPa}]$ & 161.9 & 94.9 & -0.557 \\
\hline$\sigma_{3}[\mathrm{MPa}]$ & 37.79 & 23.32 & -9.894 \\
\hline$\varepsilon_{1}\left[10^{-4}\right]$ & 29.87 & 17.43 & 1.175 \\
\hline$\varepsilon_{3}\left[10^{-4}\right]$ & -14.03 & -7.951 & -2.271 \\
\hline$\varepsilon_{f}^{\prime}$ & 0.446 & 0.446 & 0.446 \\
\hline$c$ & -0.759 & -0.759 & -0.759 \\
\hline \multirow[t]{2}{*}{$2 N_{f}$} & 1434 & 3026 & 31099 \\
\hline & $\mathrm{LP} 1_{\mathrm{B}}$ & $\mathrm{LP} 2_{\mathrm{B}}$ & $\mathrm{LP}_{\mathrm{B}}$ \\
\hline$\sigma_{1}[\mathrm{MPa}]$ & -14.5 & -3.469 & 8.71 \\
\hline$\sigma_{3}[\mathrm{MPa}]$ & -125.7 & -65.37 & 0.7058 \\
\hline$\varepsilon_{1}\left[10^{-4}\right]$ & 13.12 & 7.349 & 1.662 \\
\hline$\varepsilon_{3}\left[10^{-4}\right]$ & -24.08 & -12.89 & -0.877 \\
\hline$\varepsilon_{f}^{\prime}$ & 0.446 & 0.446 & 0.446 \\
\hline$c$ & $\begin{array}{c}-0.759 \\
\end{array}$ & 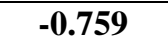 & $\begin{array}{l}-0.759 \\
\end{array}$ \\
\hline $2 N_{f}$ & 1598 & 3392 & 58733 \\
\hline
\end{tabular}
physical sense, since load intensity, position, orientation, and duration play a key role in fatigue life.
Table 3. Coffin-Manson relation input data and fatigue life results. 
The results stress a common fact that aircraft taxi, takeoff, and landing operations have a much higher impact on landing gear leg fatigue life than the impact of loads in flight.

\section{ACCUMUlated DAMAge}

Light sport aircraft are usually flown in flight profiles lasting about one hour. Maintenance actions are usually scheduled on aircraft operation hours. It is, therefore, usual to establish operation hours as a frame of reference in fatigue life calculations. Within the time of one average flight operation, the aircraft encounters the first load profile twice, before takeoff and after landing. The second load profile is also encountered twice, during takeoff and landing. The third load profile is encountered only once.

Every load profile generates a damage increment that eventually piles up to fatigue failure. Damage accumulation happens in every part of the subject's body, so in order to predict fatigue failure, the part which accumulates damage the most has to be identified. For that reason, two damage locations, A and B, with the highest Von Mises stress, have been identified. Damage accumulation in each of those locations can be calculated with the Palmgren-Miner linear damage rule. According to Palmgren-Miner, accumulated damage is equal to the sum of experienced, versus predicted fatigue cycles. In order to illustrate fatigue accumulation, an example was calculated next.

This example assumes the aircraft has 350 flight hours in total. From those 350 hours, $20 \%$ were at maximum takeoff mass, and $80 \%$ wherewith the same baggage and fuel mass, but only one single pilot (weighing in at $75 \mathrm{~kg}$ ). Damage accumulation will happen the fastest in the most stressed location, in our case that would be location A. Now the relevant load profile predictions from Table 4., can be extracted:

\begin{tabular}{|c|c|c|}
\hline & $20 \%$ MTOM & $80 \%$ SINGLE PILOT \\
\hline LP1 & $762 / 2=381$ & $1434 / 2=717$ \\
\hline LP2 & $1612 / 2=806$ & $3026 / 2=1513$ \\
\hline LP3 & & 31099 \\
\hline
\end{tabular}

Table 4. First damage accumulation example-relevant load profile predictions.

Note: accumulated damage at LP1 \& LP2 is divided by two because those load profiles are encountered twice in one flight.

$$
\begin{aligned}
& \frac{\underbrace{0.2 \cdot 350}}{381}+\frac{0.2 \cdot 350}{806}+\underbrace{\frac{0.8 \cdot 350}{717}+\frac{0.8 \cdot 350}{1513}}+\underbrace{\frac{350}{31099}}=0.8577 \\
& \text { MTOM Single pilot MTOM \& } \\
& \text { LP1 \&LP2 LP1\&LP2 Single pilot } \\
& \text { LP3 }
\end{aligned}
$$

\section{RESUlt ASSESSMENT}

The result form equation (4), states that $85.77 \%$ of the landing gear leg fatigue life has been exhausted. That aircraft could, therefore, experience failure in fatigue location $\mathrm{A}$ at 399.8 hours. In one such case, the landing gear leg of the same model as the article's subject, failed in stress location A, at 400 hours. The prescribed replacement interval was at 300 hours, so it was 100 hours past its limit. The cross-section of rupture location A showed a series of concentric markings, commonly referred to as beach marks. These markings were a clear indicator of fatigue failure, shown in Figure 13.

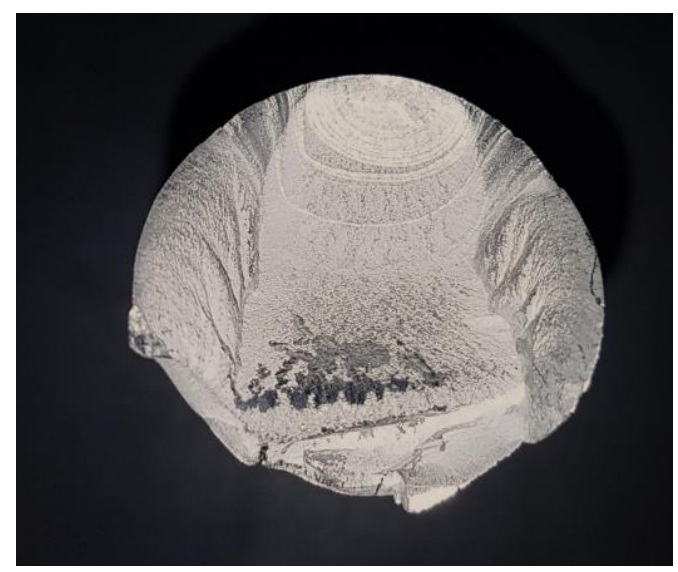

Figure 13. Landing gear leg cross-section, at fatigue location A.

This finding leads to reconsider the built-in safety factor. The replacement interval of existing landing gear systems was shortened, and modifications where undertaken in order to increase fatigue resistance.

\section{Conclusion}

Fatigue life assessment is essential in structures with low safety factors. Some of those structures are aeronautical, for example, light sport aircraft. Maintenance of light sport aircraft is, in part, may be carried out by the pilot/owner, who uses the aircraft for recreational purposes. Maintenance schedules have to be unambiguously and simple, while at the same time flexible according to operational conditions. Operational conditions of light sport aircraft are mostly influenced by their takeoff mass, which can be bigger than the aircraft empty weight for as much as $40 \%$. Additionally, light sport aircraft have strictly limited meteorological conditions and flight maneuvers acceptable for operation. Aircraft takeoff mass and operation hours are, therefore, key variables influencing landing gear leg fatigue life.

The landing gear legs of most light sport aircraft are subject to a hard time replacement interval. Aircraft manufacturers usually predict one single fatigue life before replacement, this cannot hold true for all operational conditions. An actual fatigue life smaller or close to the manufacturers predicted replacement time is a safety hazard. A table displaying 
various fatigue life predictions, depending on aircraft takeoff mass and accumulated operation hours, would increase safety, and ultimately, lower maintenance costs. Additionally, real-time RUL prediction could performed by integrating an expert system. The system would measure landing gear leg load (for example - by means of a strain gauge or accelerometer) and operation time, connecting those values to an established table containing accumulated damage, calculated with this method.

Estimating fatigue life includes assumptions, such as the three load profiles in this article. The load profiles have to be set up in a case by case manner. The Coffin-Manson relation was utilized with existing fatigue constants, which have a detrimental impact on the results; they should be considered carefully, each time a different part is analyzed. External factors such as runway roughness, temperature fluctuations, environmental corrosivity, rough landings, flight profile, existing internal or external damage, and others were not considered, they can be the cause of very different actual fatigue lives. Every underestimating fatigue life calculation contributes to safety at the expense of economic factors. Tailoring maintenance schedules to specific use patterns can benefit both. Further research on this subject could include method validation on other various low cycle metal fatigue aircraft parts. Also, a comparison with other fatigue life prediction methods could benefit method implementation and expose other method limitations.

\section{NOMENCLATURE}

$\begin{array}{ll}A & \text { Primary failure location } \\ B & \text { Secondary failure location } \\ C A D & \text { Computer Animated Design } \\ \text { E } & \text { Modul of elasticity (Young's modulus) } \\ F E M & \text { Finite Element Method } \\ \text { LP1 } & \text { Load profile 1 } \\ \text { LP2 } & \text { Load profile 2 } \\ \text { LP3 } & \text { Load profile 3 } \\ L P 1_{A} & \text { Load profile 1, for primary failure location A } \\ L P 2_{A} & \text { Load profile 2, at primary failure location A } \\ L P 3_{A} & \text { Load profile 3, at primary failure location A } \\ L P 1_{B} & \text { Load profile 1, at primary failure location B } \\ L P 2_{B} & \text { Load profile 2, at primary failure location B } \\ L P 3_{B} & \text { Load profile 3, at primary failure location B } \\ L P 1_{M T O M} & \text { Load profile 1, at maximum takeoff mass }\end{array}$

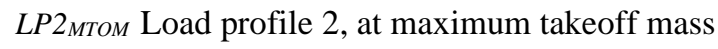

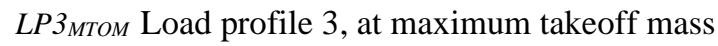

$\mathrm{LP} 1_{\mathrm{A}, \mathrm{MTOM}}$ Load profile 1 , for failure location $\mathrm{A}$ at maximum takeoff mass

LP2 2 A,MTOм Load profile 2, for failure location $\mathrm{A}$ at maximum takeoff mass

$\mathrm{LP}_{\mathrm{A}, \mathrm{MTOM}}$ Load profile 3, for failure location $\mathrm{A}$ at maximum takeoff mass

$\mathrm{LP}_{\mathrm{B}, \mathrm{MTOM}}$ Load profile 1, for failure location $\mathrm{B}$ at maximum takeoff mass

LP2 takeoff mass

LP3в,мтом Load profile 1, for failure location B at maximum takeoff mass

MTOM Maximum takeoff mass

$\sigma_{1} \quad$ First principal stress

$\sigma_{3} \quad$ Third principal stress

$\varepsilon_{1} \quad$ First principal strain

$\varepsilon_{3} \quad$ Third principal strain

$\sigma_{v, A m a x}$ Von Mises stress at primary failure location A

$\sigma_{v, B \max }$ Von Mises stress at primary failure location B

$\Delta \varepsilon_{p} \quad$ Plastic strain range

$\Delta \varepsilon_{e} \quad$ Elastic strain range

$\Delta \varepsilon_{\text {total }}$ Total strain range

$\varepsilon_{f}^{\prime} \quad$ Fatigue ductility coefficient

$2 N_{f} \quad$ Number of strain reversals to failure

c Fatigue ductility exponent

8 Constraint lock - the movement of marked surface and connected geometry is fully constrained

\section{REFERENCES}

Rastogi, M. (2016). Probabilistic Method to predict Remaining Usage Life of Aircraft Structures. Proceedings of European Conference of the Prognostics and Health Management Society 2016. July 5-8, Bilbao, Spain. ISBN: 978-1-936263-21.

Campbell, G. S., Lahey, R. (1984). A survey of serious aircraft accidents involving fatigue fracture. International Journal of Fatigue, vol. 1, pp. 25-30. doi: 10.1016/0142-1123(84)90005-7

Cui, W., (2002). A state-of-the-art review on fatigue life prediction methods for metal structures. Journal of marine science and technology 7. vol. (1), pp. 43-56. doi: $10.1007 / \mathrm{s} 007730200012$ 
European Parliament and Council (2008). Regulation (EC) No 216/2008 of the Common rules in the field of civil aviation and establishing a European Aviation Safety Agency, and repealing Council Directive 91/670/EEC.

Boller, C., Seeger, T. (1987). Materials Data for Cyclic Loading. Part D: Aluminum and Titanium Alloys. Elsevier Science Publishers, 165.

Campbell, F. C., editor (2008). Elements of metallurgy and engineering alloys. ASM International.

\section{BIOGRAPHIES}

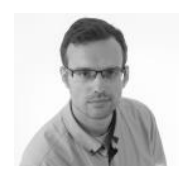

David Gerhardinger, born Zagreb, 18. October 1986., is full-time involved with aeronautics since 2001. He earned the Master of Aeronautical Engineering degree (2014) and the university bachelor's degree in aeronautical engineering (2012) from the Faculty of Mechanical Engineering and Naval Architecture at the University in Zagreb. Prior to that, he graduated at the Aeronautical technical school in Zagreb (2005), where he was educated as an aeronautical technician. His work experience involves three years as a production manager and $R \& D$ engineer at Alpi Aviation, where he managed the production of 51 pioneer airplane and the assembly of 16 Syton helicopter composite bodies, as well as some minor product modifications. At present, he is a Ph.D. student and a teaching and research assistant at the Department for Aeronautics and a court expertise coordinator and court expert for airframes, systems and powerplant at the department for TechnicalTraffic Assessment, all at the Faculty of Transport and Traffic Sciences, University in Zagreb. His main research interest is prognostics and health management in aeronautics.

Anita Domitrović, PhD and Ernest Bazijanac PhD, both are professors at the Faculty of Transport and Traffic Sciences, at the University in Zagreb. They work at the Department for Aeronautics, and both have a rich research and teaching experience in aircraft maintenance. 